\title{
Family perceptions in caring for children and adolescents with mental disabilities: a qualitative study from Tanzania
}

\author{
G.S.K. MBWILO', B. SMIDE² and C. AARTS ${ }^{3 *}$ \\ ${ }^{1}$ Muhimbili University of Health and Allied Sciences, Institute of Allied Health Sciences, School of Nurse \\ Teachers, Dar es Salaam, Tanzania \\ ${ }^{2}$ Department of Medical Sciences, Uppsala University, Sweden \\ ${ }^{3}$ Department of Public Health and Caring Sciences, Caring Sciences, Uppsala University, Sweden
}

\begin{abstract}
Observations have shown that the provision of services to children and adolescents with mental disability (CAMDs) is not responding to the needs of this population. This community based study was carried out in Temeke Municipality in Tanzania and aimed to explore factors that influence family perspectives in the provision of care to CAMDs. This is a qualitative study of 52 respondents from 29 families involved in the daily care of CAMDs, chosen through convenient sampling. A semistructured questionnaire was used in the interviews. The text was analysed using thematic content analysis. The results of the study revealed family characteristics; deficient knowledge about mental disability (MD); and lack of health care facilities and resources for caring for CAMDs. The community and families of CAMDs had poor knowledge on MD and appropriate care, and about availability of resources and quality care. Families were not supported in the care of their children. Some children in consequence did not receive adequate health care. Some suffered from physical problems due to inadequate care; others were being locked in their room during periods when no-one was able to look after them. These factors were related to socio-economic characteristics of the families as well as to lacking service facilities. "Patient"-oriented, community/family-based health services to support management of chronic or life-long conditions such as MD are needed. The support of caregivers to children with MDs has to be improved. A well worked-out strategy would improve health care of CAMDs through provision of guidance and supervision to the families. Community and family/home-based care in the study area would benefit families of CAMDs.
\end{abstract}

Key words: children, adolescents, mental health, disability, Tanzania

\section{Introduction}

Mental health in Tanzania falls under primary health care. It is provided through dispensaries and health centres and by mental health nurses and general health workers (WHO, 2005). There are some few mental health facilities, but these are for adults only. Children with mental disabilities (MDs) receive health services in general wards. A mental health service for children and adolescents is a new field to be developed in the country.

There is no uniform definition of "mental disability". It is generally accepted that MD, sometimes referred to as "mental deficiency", "developmental delay" or "cognitive disabilities", is a condition in which there is arrest in the development of the mind. A mental deficit is accompanied by impairment of skills and intellectual capacity in areas of cognition and motor and social abilities (Mereness \& Tailor, 1978; Hawkins-Shepard, 1994; WHO, 2001; Johnson, 2007). Mental retardation is one of the well-studied MDs and is defined in relation to mastery of the immediate environment. Authors agree that mental retardation is a state in which functioning is impaired in certain specific ways and occurs within the context of the

\footnotetext{
* Correspondence: Clara Aarts; E-mail: clara.aarts@pubcare.uu.se
} 
community environment (Hawkins-Shepard, 1994; Smith, 2005; WHO, 2001). The World Health Organization states that mental health is more than the absence of mental disorders. Mental disorders include mental, neurological and behavioural disorders (WHO, 2008). In this study we use the term "mental disability" to represent groups of MDs such as mental retardation, Down's syndrome and microcephaly. Cerebral palsy, hyperactivity and learning disability are also included.

Mental disability is associated with multifaceted risk factors (Merenes \& Taylor, 1978; Mgone, 1983; Mental Health, 2001; Waddell et al., 2002; Voss et al., 2007). Unfavourable conditions during foetal life and traumatic factors during delivery may determine the mental status of children. Other factors are biological influences such as abnormal central nervous system, genetic factors, infections, poor nutrition and exposure to toxins. Further, psychosocial factors include dysfunctional family ties, parental psychopathology, large family size, poverty, and parenting styles and temperament. Even stressful events are thought to be linked to mental disabilities such as natural disasters. Peer group sibling influences - maladaptive peers and aggressiveness influence mental disorders in children.

Traditionally MD is associated with socio-cultural beliefs of a curse, of misfortune, and punishment from ancestors. It is associated with superstitions and religious beliefs (Ngatunga, 2004). Having a child with MD affects families in a number of ways. Sen \& Yurtsever (2007) observed that the birth of the child with MD in a family is a crisis in which the parents' expectations are turned upside down. The few studies conducted in Tanzania reveal that communities are given inadequate information about MD (Mgone, 1983; Katole, 1988; Adam, 2001). Many adolescents with MD are mistreated (e.g. sexually abused), or isolated, hidden away from the public; much of their mistreatment is due to fear of them. Furthermore, they are deprived of essential services including health care, education, food and social benefits. Many live in poor living conditions and their life expectancy is often shortened (Katole, 1988; Ngatunga, 2004). However, some efforts have been made in Tanzania by societies and organizations to improve their lot. These include advocacy, education on human rights, empowerment and development of policies governing MD (Ngatunga, 2004).

Mental disability in a family is perceived in different ways and creates uncertainty for parents, family members and the community at large. It is important that health care providers have an in-depth understanding of the experiences encountered by these families. This study aims to explore family perspectives in caring for CAMDs. The research questions were: What are the perceptions of MD among relatives caring for children with MD, and what care do they seek? What are the major needs, and how do relatives try to meet these needs? What are the challenges faced by the relatives caring for a child with MD? How can mental health services for children with MD be improved?

\section{Materials and Methods}

\section{Study area, design and participants}

This community based exploratory study was conducted in Temeke Municipality in Dar es Salaam, Tanzania. Temeke Municipality is located between latitude 655'S and longitude $39^{\circ} 25^{\prime} \mathrm{E}$ and forms the southernmost part of the Dar es Salaam City. The municipal total area is $786.55 \mathrm{~km}^{2}$ and an estimated population of 780,000 (URT, 2003).

Fifty-two participants from 29 families were included. The participants were contacted through local government offices, through two special schools for CAMDs and through snow- 
ball sampling, i.e. one family knew another family who had a child with MD. The two CAMD schools were selected as they were within walking distance of each other, which facilitated administration of the questionnaire. The number of pupils in these two schools was 128 (87 male and 41 female pupils). The inclusion criteria were having a child or adolescent family member with known MD and being involved in the care of that child or adolescent; as well as willingness to participate, ability to express themselves in English or Kiswahili, and living in an area that is accessible by public transportation.

The study used snow-ball sampling, which was the only method that made it possible to find the families, since not all are known by the government. The participants were the close caregivers and they were rich in information about the children. In qualitative studies, in-depth information is necessary. For this reason, we chose to interview 52 participants although saturation point was reached at the $40^{\text {th }}$ interview. However, all the participants contributed greatly to the study, especially regarding challenges involved and improvement needed in the care of children with MD.

\section{Interviews}

Parents and relatives of children with MD were interviewed using semi-structured questionnaires. The questionnaire comprised 25 items. Fifteen dealt with background data on the children/adolescents and study participants. The main research areas were: (a) perceptions of causes of MD; (b) major needs and ways of meeting the needs; (c) challenges for families in caring for CAMDs; and (d) suggestions for improving mental health services for these children and adolescents.

The interviews were held privately in a familiar environment at participants' homes. Each day the collected data were reviewed and, where necessary, a revisit was scheduled. The interviews were recorded on paper as well as tape-recorded. Each interview lasted for approximately 2 hours. The language of communication was Kiswahili.

The interviews were conducted in participants' homes, which gave the participants freedom of expression. Each participant was interviewed privately so as to avoid influence from other family members. Holding the interviews at the homes of the participants gave the opportunity to learn other issues which were not included in the interview questionnaire, such as the home environment, practical aspects of the care of CAMDs, and the relationship with neighbours. In some cases, the interviews touched some painful experiences of participants, which caused the interviewer to halt or to move on to another topic. Sometimes, a topic was abandoned for another sensitive reason. For example, it became apparent that participants were under the impression that the study was soliciting families with special needs to receive support and assistance. Therefore the question on support had to be abandoned.

\section{Data analysis}

Except for background data, all interview data were transcribed verbatim. The text was analysed using thematic content analysis, as described by Polit \& Beck (2007). The research questions guided the data analysis. The text was read through several times to identify categories and subcategories. The emerged categories were discussed between the members of the research team until full agreement was reached. Some of the qualitative data were tabulated in order to show how common a certain phenomenon appeared to be (Polit \& Beck, 2007). 


\section{Ethical considerations}

Ethical clearance was obtained from the Director of Research and Publication of Muhimbili University of Health and Allied Sciences. Informed consent was obtained from the interviewees.

\section{Results}

\section{Socio-demographic characteristics of the respondents}

Of the 52 participants, the majority (30) were parents and the rest (22) were relatives. The participants included were eight fathers, 22 mothers, seven sisters, three brothers, four aunts, six grandmothers, one grandfather and one uncle of a child with MD. Two participants had a white-collar occupation, namely accountant and personal secretary. The others were vendors running small businesses, or unemployed. Most of the respondents (36) were $>34$ years old. Over three quarters $(78.8 \%)$ of the respondents had either primary or secondary school education (Table 1).

Table 1: Personal characteristics of 52 participants from 29 families

\begin{tabular}{|c|c|c|c|}
\hline Variables & Response & Parents & Relatives \\
\hline \multirow[t]{2}{*}{ Sex } & Female & 22 & 17 \\
\hline & Male & 8 & 5 \\
\hline \multirow[t]{2}{*}{ Age (years) } & $18-34$ & 5 & 11 \\
\hline & $>34$ & 25 & 11 \\
\hline \multirow[t]{3}{*}{ Education } & Adult education & 1 & 0 \\
\hline & Primary/Secondary school & 24 & 17 \\
\hline & Illiterate & 5 & 5 \\
\hline \multirow[t]{2}{*}{ Religion } & Moslem & 21 & 13 \\
\hline & Christian & 9 & 9 \\
\hline
\end{tabular}

\section{Particulars of children and adolescents}

All children with MD included in the study had been traced through local resources. The main reasons for MD as perceived by the caregivers were mental retardation $(n=10)$, cerebral palsy $(\mathrm{n}=7)$ and learning disability $(\mathrm{n}=6)$ (Table 2).

Table 2: Mental disability among children and adolescents as perceived by the caregivers

\begin{tabular}{lll}
\hline Mental disability & Number of children (\%) & Percentage \\
\hline Cerebral palsy $^{1}$ & 7 & 24.1 \\
Mental retardation $^{2}$ & 10 & 34.5 \\
Autism & 1 & 3.4 \\
Hyperactivity & 4 & 13.8 \\
Microcephaly & 1 & 3.4 \\
Learning disability $^{3}$ & 6 & 20.7 \\
\hline rebral palsy: The child is not growing well when compared with other children of the same age; his or her body is stiff, rigid \\
d skinny. S/he fails to feed and help her/himself, wets clothes. Wasted muscles, drowsy. \\
ental retardation: Difficulties in coping with complex issues, slow in understanding issues, difficulties in counting and \\
membering, not stimulated by the environment, failure to follow instructions.
\end{tabular}

Half of the children were at school age (6-15 years) although 15 children did not have any school education. Fourteen children were above the age of 16 years. The onset of MD was for 
most of the children $(n=27)$ around 5 years or below, as reported by the participants (Table $3)$.

Table 3: Personal characteristics of children with mental disability (MD) whose caregivers participated in the study $(\mathrm{N}=29)$

\begin{tabular}{lll}
\hline Variable & Response & No. of children and adolescents with MD \\
\hline Sex & Female & 13 \\
F/M & Male & 16 \\
Age & $<2$ years & 1 \\
& 6-10 years & 6 \\
& 11-15 years & 6 \\
& $\geq 16$ years & 14 \\
Onset of MD & Unknown & 2 \\
& Around 5 years or below & 27 \\
Education & 6-10 years & 1 \\
& 11-15 years & 1 \\
& Primary school & 3 \\
& Special school for CAMDs & 11 \\
& No school education & 15 \\
\hline
\end{tabular}

The findings are presented under four headings, each representing a main category in relation to the aims of the study. Within each category, subcategories emerged (Table 4).

Table 4: Categories and subcategories of families' perceptions of caring for children and adolescents with mental disabilities

\begin{tabular}{|c|c|}
\hline Category & Subcategories \\
\hline Perceptions of mental disability (MD) & $\begin{array}{l}\text { A wide diversity of perceptions, } \\
\text { from positive to horrified }\end{array}$ \\
\hline Major needs and ways of meeting the needs & $\begin{array}{l}\text { Coping with } \\
\text { - basic needs } \\
\text { - education-related needs } \\
\text { - health care needs } \\
\text { - } \text { security needs } \\
\text { - socio-economic needs }\end{array}$ \\
\hline Major challenges faced by the families & $\begin{array}{l}\text { Meeting challenges of } \\
\text { - discrimination } \\
\text { - interpersonal relationships } \\
\text { - concerns for the future }\end{array}$ \\
\hline Improvement of mental health services & $\begin{array}{l}\text { Need for improvement in } \\
\text { - health care } \\
\text { - } \text { education } \\
\text { - } \\
\text { socio-economic services }\end{array}$ \\
\hline
\end{tabular}

\section{Family members' perceptions}

About one-third of participants perceived the presence of the child positively; others were horrified because their child was disabled. Some of the parents had separated and left home. Factors mentioned contributing to MD were high fever and convulsions associated with malaria or other sources of fever. Some blamed nature or God. Others linked MD to low birth weight or the polio vaccine. Still others were not aware of the cause of MD as described by 
two different mothers. One had these say: "I received the child normally but my husband received the situation negatively after learning that the child is like this" Another mother added: "I was puzzled on learning that the child was showing abnormal symptoms"

\section{Major needs and ways of meeting the needs}

The major needs and coping with these needs were divided into five subcategories, namely, basic, education-related, health-care, security-related and economic needs.

(i) Basic needs: These needs refer to daily routines at home. Different strategies, depending on the child's abilities, were used to encourage independence, such as at mealtimes as described by two mothers: "It is tiresome to care for her. She does not help herself. She does not eat alone. We crush food and feed her. . ". "We give him the same food that we eat. We don't make special food for him as our financial position is not good"

Caring requires tolerance, commitment and time. It involves giving life-long support and requires skills to give the necessary care. Families claimed that they had not been given guidance on how to care for the child. They had to provide care in the way they considered most appropriate. This led to physical problems in some children, such as development of bedsores and contracture of limbs.

One of the challenging and most frequently told experiences was helping with going to the toilet. The mothers and sisters of disabled girls who were unable to care for themselves had to provide this help. The stepmother of a severely disabled adolescent aged 16 years described this part of care giving as torture: "She defecates without any notice. There comes a time when a child defecates and you don't even want to wash the soiled clothes. You take and throw it in the toilet. My dear, to touch the faeces of an adult person is not proper. Adult faeces smell badly. She soils herself and her clothes. But what can I do? You can't blame her. That is a task you have to carry out daily..."

Education-related needs: Families tended to send the children to both special and ordinary schools. Accompanying the child to school was time-consuming and expensive as described by one of the fathers: "I send and collect him every day. Yes, this is the exercise. I have to do it myself. It means I have to leave the welding at my workshop so as to collect him early from school. He knows the way but he may get lost. I'm not happy with his disability". Often the child did not benefit from going to school: "I do appreciate some of changes in behaviour. She's spent 9 years at the school but she can't read and write ... I don't know what they learn there ... (Father).

Some of the children were given informal training in an effort to develop basic skills, such as tooth brushing, bathing, sweeping, toilet cleaning, cooking, getting dressed and washing clothes. The training was gender-related. The girls were taught the tasks that their mothers performed, while the boys were taught to do the work, or some of the work, their fathers did. This depended much on the families' own initiative. One of the fathers had these to say: He is interested in technical tasks. I think he could benefit more if he got a chance to learn technical work"

Health care needs: These included the provision of health services, guidance from health providers and accessibility to health services. The home formed the primary level of care, while medical, traditional and religious services formed the secondary level of care. Different types of care involved consulting traditional practices to look for causes, procure treatment, and obtain a prognosis. More than half of the families opted to send their children to health care services, others to combine health care and traditional care, while some chose only traditional and religious services. Services sought from the religious organizations included healing and spiritual, moral, material and financial support. None of the parents 
selected religious care as the only care for their child, it was combined with other services available in the community as it was described by one of the fathers: "Yes, it's important to combine types of care when the condition of the child is not improving. The condition of the child forced us to seek services from other sources. You run for it once you get informed". The children were sent to facilities more often during the first years of their illness. The older the "patient", the less frequent the visits to various services. The caregivers played a central role in coordinating theses services.

Some participants claimed that they had been offered health services very far from their place of residence, which was the reason why the caregivers did not consult health providers on a regular basis. A mother had these to say: "We don't have such services near our homes. We get such services at Muhimbili National Hospital, which is far away from here". Muhimbili National Hospital is about $15-30 \mathrm{~km}$ from area where this study was conducted. Therefore, some of the families had stopped sending their child to hospitals for monitoring purposes. However, they accepted that health care services are important in acute illness. The participants further said they needed guidance in managing their child at home. The long queues at many public health care facilities were experienced as a source of discomfort, since many people stared at their child while waiting.

Security-related needs: The families played an important role in safeguarding the child from injury and injustices from immediate community members. This included offering some form of controlled freedom and restricted movement. For instance, a child with poor memory might be restricted in moving around the home. Some participants said that most of their time was spent looking after the child for security reasons. One family locked their adolescent girl in a room and left her alone whenever the parent needed to go out on homerelated chores. Another family built a strong room within the corridor of the house to keep the adolescent indoors during hyperactive behaviour. The family believed that restraining the boy was necessary to manage him at home and protect him as described by one of the fathers: "I have no alternative. At times the boy is very difficult and troublesome. This is the way we have thought to protect him from mistreatment by neighbours"

Socio-economic needs: The support of the families from different stakeholders and services that assist families was assessed. Almost all participants said they had received no support from governmental or non-governmental organizations. Many families struggled to meet their basic daily needs. One of the fathers had these to say: "I don't have a car to send my child to and from services such as religious meetings of healing. You know, when someone is sick in the family, you need to struggle to get something to eat and pay the rent. ........I search and search for money to buy Panadol for her". The families received support only from the members of the nuclear and extended family. The support was in the form of materials like food, clothes, bed sheets and money. Some families took over all responsibilities of the nuclear family. One family was assisted by a "good Samaritan" who built a house for them.

\section{Major challenges faced by the families}

Major challenges faced by families were discrimination, interpersonal relationships and concerns for the future.

Discrimination: The participants shared grievances about the community. They said the community did not recognize the enormity of the task involved in taking care of a child with MD. Some community members harboured prejudices and superstitions and discriminated against families with a child with MD as described by one of the fathers: "People start looking at you and the child who is salivating now and then. It induces stigma and 
discrimination among us". Moreover, some of the actions of the child created bad relationships with neighbours. A mother had these to say: "I'm so troubled. It is discrimination. There are some people who say that we should move away. Where should we move where people will accept such bad behaviour of our child? Truly I have no peace of mind. Do they think I chose to bear a child of this kind? It is hard and painful"

Another example came from a family with a hyperactive child. The boy was making a nuisance of himself in the neighbourhood. He was destructive and stealing goods from neighbours. The family had to reimburse money for items stolen or damaged by the boy. At times the boy was mistreated, beaten up and sexually abused by other children. This made the parents watchful of their child's movements. His mother cried when discussing challenges relating to his care. "I have to reimburse money for items damaged or stolen from neighbours. As a parent, what should I do? Perhaps it's God's wish to lead us to temptations. Sometimes he is seriously beaten up. They even said to me or his mother!, that they will poison him"

Interpersonal relationships: Communication between the caretakers and the child was seen as a hindrance to providing care. The problems included failure to understand the needs of the child or adolescent; misinterpreting non-verbal signs; missing the behaviour expressed by the child or adolescent; and situations when the child or adolescent would act differently to what they were told. "The communication with this child is through my own intellectual abilities. For example, refusal to eat means he does not like the food. I don't know if he pretends [not to understand]. You ask to do this, he does the opposite" (Father).

Some participants said that the children were taught by family members to modify their behaviour so as to be good citizens and be acceptable to the family and the community. In some instances, participants had to give the child negative feedback for behaviour or inappropriate language. At times, parents and significant others gave some form of punishment immediately in response to inappropriate behaviour as testified by one of the fathers: "Sometimes as a parent you have to punish him. If you don't do it at the right time he may fail to understand that there's a problem. You know he may do it on purpose"

Concerns for the future: Parents were very concerned about the future development of their child and they were worried about whether they would be able to sustain the life of the child. Families were also concerned with the growth and mental development of their child as compared with expected levels for that age: I'm not worried ... but what does worry me is his development. How can I ensure my child's development is like that of other children? After completing special school education, he needs something to make him advance further. His performance is not good. Who will be responsible when us parents die? What will be his fate in the future?" (Father).

\section{Participant's suggestions for improvement of mental health services}

Health care, education and socio-economic services

These were prominently referred to more often than any other services. There should be coordination in distribution of services provided by government, non-governmental organizations, private institutions and individual persons on a humanitarian basis. Clinics are needed that specialize in MD children. Clinics need adequate resources, which need to be provided free of charge. Families should be made aware of existing facilities and be encouraged to use them. Furthermore, community/home-based MD services should be made available, with participation by the community. Also, information to and education of caregivers as well as community members is needed. 
More government-owned schools are needed, including schools providing special education for children with MD. These should be well equipped with resources both human and material, and should provide education free of charge or at reduced fees. Private organizations should be invited to establish, or provide funding for schools or other services for children with MD. Parents or guardians should be encouraged to be involved in running these schools through representation. The afflicted families would furthermore benefit from financial assistance through grants and interest-free loans. Some might benefit from help with income generation. Public services should be offered free of charge.

\section{Discussion}

The results show that the major needs of the child are related to basic needs, education, health care and security, and that families need socio-economic support. Other challenges faced by the families are discrimination, interpersonal relationships and concerns for the future. A child with MD is a heavy burden for the family. There is a great need for support from the community and society.

Caregivers were both men and women, although the majority were women. This is in agreement with Sen\& Yurtsever (2007) who found that men participated less than women in the provision of care to their disabled ones. In Tanzania, however, it is normally the woman who takes responsibility for household chores and child raising (Mgone, 1983) as experienced in this study.

About one-third of participants in this study claimed that they had perceived the presence of $\mathrm{MD}$ in their families positively. This perception has repercussions on the management of the child. However, their claim was difficult to substantiate. During the interviews some of the participants who said they had perceived the birth of the child in their families positively later expressed negative feelings about MD in their family. They complained bitterly about tasks relating to the care of their charges. This contradiction may be explained by the fact that the participants wanted to answer "correctly"; many are religious and having a child with MD is seen as God's will, which has to be accepted. Some studies have shown that very often parents have a negative attitude towards their children with disabilities (Rangaswami, 1995; Gupta \& Singhal, 2004).

Interestingly, many were able to identify factors that contribute to MD. Severe malaria and other sources of high fever, together with low birth weight, are viewed as contributing factors to MD (Mental Health, 2001; Merenes \& Taylor 1978). Those who thought that the polio vaccine had caused MD may have linked the disability to the vaccination because they had first noticed the MD in their child around the time of the polio vaccination. This indicates knowledge deficit about MD, among the participants. The need to educate the public on these factors is evident, which action may reduce the stigma and discrimination among people in the community.

The participants were parents and close relatives of families of children with MD, including grandparents, aunts, sisters and brothers and an uncle. The participation of the extended family in the provision of health care ensures that family members feel responsible for the "patient". The need to support families with children with MD is emphasized by many authors (Mental Health, 2001; DDF, 2001; WFMH, 2003; Ngatunga, 2004; Sen \& Yurtsever, 2007; WHO, 2007). This support is necessary since the families are faced with additional responsibilities and they experience many problems relating to the care. In the children in this study who developed bedsores and contractures of limbs, these problems 
could have been prevented if the families had been supported earlier in their homes (Mgone, 1983; Katole, 1988; Hawkins-Shepard 1994; Adam 2001; Ngatunga, 2004).

In the study population, families sought help not only from health care services but also from different sources, irrespective of their religious background. The participants took the child to traditional healers to get a remedy for MD.

The problem of interpersonal relationships in managing disabled children and adolescents needs to be highlighted. Attree (2000) found that interpersonal relationships are central to the quality of care for patients. The author noted that the technical aspects of care received less recognition in care outcomes in comparison with interpersonal relationships. Lau (1996) noted that quality of care is based on the interpersonal relationships of nurses with their clients in activities of daily living.

The special education needs of children with MD seem to have received very little attention from society. The government has put little effort into establishing schools for mentally disabled children. Education was one of the social difficulties experienced by many of the families in this study. The learning environment was described to lack motivation for the disabled child. Many families expressed concerns that their children were not benefiting from schooling. These children need well- programmed sessions to benefit them. This requires teachers who are well trained and equipped to teach CAMDs. The education of CAMDs should include areas of life skills from early life (Hawkins-Shepard, 1994; Roberts \& Lawton, 2001). Also, it is doubtful whether disabled children undergo mental assessment prior to admission to school - another area to be addressed.

Economic difficulties experienced by the families affected the provision of the care of the child, with difficulties to sustain basic needs, education as well as housing, as also reported in other studies (Emerson \& Hatton, 2007; Sen \& Yurtsever, 2007). The participants told about discrimination against children with MD. Many studies have reported that persons with MD experience stigma and discrimination in society (Mental Health, 2001; Howell \& McFeeters, 2008). Furthermore, participants expressed deep concerns about the future when there would come a time when they would no longer be able to take responsibility for the person with MD. This is in agreement with other studies conducted in different settings (Hawkins-Shepard, 1994; Roberts \& Lawton, 2001).

Family perspectives in the care of children with MD in developing counties are under researched. Families do not receive supervision and professional guidance. Special schools for children with MD are lacking. In the present study, the families and the community were found to have little knowledge about MD. In general, myths and misconceptions about MD, and people with MD, exist in the community and even within the family. This makes it difficult for families with CAMDs to adequately care for the children.

Caring for a person with MD requires many resources which cannot be provided by service facilities alone. Volunteers are required to safeguard CAMDs from entering into difficulties. The health sector, together with other stakeholders, local, national as well as international, should work out ways of keeping this "silent population" safe from the difficulties they currently experience.

A number of issues can be drawn from the study for betterment of the "patients" and improvement of health care facilities. The results of the study can be used in devising strategies to secure the participation of families in the care of children with MD at health facilities and community levels. Central to this is the fact that the care of CAMDs combines many approaches that need to be coordinated effectively by health personnel. Hence, the 
health care facilities should devise modalities or modify existing modalities of care in an effort to promote the quality of care, especially at the family level. In psychiatric nursing training, the curriculum should emphasize clinical practice both in mental rehabilitation units and in the community.

\section{Acknowledgements}

The authors owe many thanks to the families who have devoted their time to care for this silent population and who gave their time to share their thoughts at the interviews. The study was funded by research funds through Muhimbili University of Health and Allied Sciences and Indevelop Sweden.

Received 31 December 2009

Accepted 23 March 2010

\section{References}

Adam, N. (2001) Assessment of Quality of Services in Primary Health Care Facilities in Moshi Rural District. University Press, Dar es Salaam.

Attree, M. (2000) "Patients'" and relatives' experiences and perspectives of "good" and "not so good" quality care. Journal of Advanced Nursing 33, 456-466.

DDF (2001) Delaware Disabilities Forum: Report of Conference on Strategies for Improving Services to Children with Mental and Cognitive Disabilities and their Families. Department of Justice, Wilmington (Available at: http://www.state.de.us/attgen/brochures/disable for/improserv.htm. (Accessed on 5 October 2004).

Emerson, E. \& Hatton, C. (2007) Poverty, socio-economic position, social capital and health of children and adolescents with intellectual disabilities in Britain: a replication. Journal of Intellectual Disability Research, 51, 866-874.

Gupta, A. \& Singhal, N. (2004) Positive perceptions in parents of children with disabilities. Asian Pacific Disability Rehabilitation Journal 15, 22-35.

Hawkins-Shepard, C. (1994) Mental Retardation (Available at: $\underline{\text { http://ericac.org/digest/e528.html }}$ - (Accessed on 20 September 2005).

Howell, E. \& McFeeters, J. (2008) Children's Mental Health Care: Differences by Race/Ethnicity in Urban/Rural Areas. Journal of Health Care for the Poor and Underserved 19, 237-247.

Johnson, M.H. (2007) Developing a Social Brain. Acta Paediatrica 96, 3-5.

Katole, N.B. (1988) Study on Mental Retardation in Children in Dar-es-Salaam. Medical Library. Dissertation for Doctoral Degree, University of Dar es Salaam, Tanzania.

Lau, V.M.H. (1996) Attributes of Nurses that Determine the Quality of Care for Mentally Handicapped People in an Institution. Journal of Advanced Nursing 24, 1109-1114.

Mental Health (2001) A report by the Surgeon General (Available at: http://www.surgeon.general.gov/library/mental health (Accessed on 20 December 2005)

Mereness D. \& Taylor C.M. (1978) Essentials of Psychiatric Nursing. The Mosby Company, St. Louis, MO.

Mgone, J.M. (1983) Major Congenital Malformations in Dar-es-Salaam. Medical Library. Dissertation for Doctoral Degree, University of Dar es Salaam, Tanzania. 
Ngatunga, A. (2004) Parents and Community Members Can Improve the Condition of Children with Mental Disability. Community-Based Rehabilitation Africa Network, Kampala, Uganda (Available at http://www.afri-can.org/ngatunga.html. (Accessed 23 February 2009).

Polit, D.F. \& Beck, C.T. (2007) Nursing Research: Principle and Methods. Lippincott Williams \& Wilkins, Philadelphia, PA.

Rangaswami, K. (1995) Parental attitude towards mentally retarded children. Indian Journal of Clinical Psychology 22, 20-23.

Roberts, K., \& Lawton, D. (2001) Acknowledging the Extra Care Patients Give their Disabled Children. Child Care. Health and Development 27, 307-319.

Sen, E., \& Yurtsever, S. (2007) Difficulties Experienced by Families with Disabled Children. Journal for Specialists in Paediatric Nursing 12, 238-252.

Smith, J.F. (2005) Mental Retardation (Available at http://www.chclibrary.org/micromed/00056550. (Accessed on 20 September 2008).

URT (2003) 2002 Population and Housing Census General Report. Central Census Office. National Bureau of Statistics, President's Office, Planning and Privatization. Government Printers, Tanzania. 203 pp.

Voss, W., Neubauer, A.P., Wachtendorf, M., Verhey, J.F. \& Kattner, E. (2007) Neurodevelopmental Outcome in Extreme Birth Weight Infants: What is the Minimum Age for Reliable Development Prognosis? Acta Paediatrica: Promoting Child Health 96, 342-347.

Waddell, C., McEwan, K., Hua, I., \& Shephard, C. (2002) Child and Youth Mental Health: Population Health and Clinical Service Considerations. The University of Columbia, Vancouver, B.C., Canada.

WHO (2001) The World Health Report 2001: Mental Health: New Understanding New Hope. World Health Organization, Geneva.

WHO (2005) Mental Health Atlas 2005. United Republic of Tanzania. World Health Organization, Geneva. (Available at http://www.who.int/mediacentre/news/notes/2005/np21/en/index.html. (Accessed on 23 February 2009).

WHO (2007) Mental Health: Strengthening Mental Health Promotion. Fact sheet No. 220. September 2007. World Health Organization, Geneva. (Available at http://www.who.int/mental health/en/. (Accessed on 12 October 2009).

WHO (2008) Mental Health, Human Rights and Legislation: WHO's Framework. World Health Organization, Geneva. (Available at http://www.who.int/mental_health/policy/fact_sheet_mnh_hr_leg_2105.pdf. (Accessed on 23 February 2009).

WFMH (2003) World Mental Health Day 2003: To Promote Improved Services for Young People. World Federation for Mental Health, Alexandria, VA. 